\title{
Case Report of Long Term Complete Remission of Metastatic Renal Squamous Cell Carcinoma after Palliative Radiotherapy and Adjuvant Dichloroacetate
}

\author{
Akbar Khan \\ Medical Director, Medicor Cancer Centres Inc., Toronto, Canada
}

\begin{abstract}
Renal squamous cell carcinoma is a rare form of renal cancer which is considered incurable once metastases develop. Prognosis is poor and average survival of advanced stage disease is typically in the range of several months, despite all available conventional therapies.

We describe the case of a 72 year old female with metastatic renal squamous cell carcinoma who had a radical nephrectomy with positive surgical margins, renal vein invasion and metastases to multiple abdominal lymph nodes. She received a course of palliative radiotherapy to the abdomen with 4500cGy in 25 fractions over 5 weeks. Following radiotherapy, she was treated with a cyclic regimen of oral sodium dichloroacetate ("DCA"). Treatment was discontinued after 3 months due to development of peripheral neuropathy. Follow-up imaging upon completion of DCA treatment revealed no sign of metastatic disease. The neuropathy gradually improved and computed tomography imaging four years later demonstrated no cancer recurrence. The patient continues to feel well with no clinical evidence of recurrence five years after completion of therapy, and is living a normal and active life.
\end{abstract}

Keywords: Dichloroacetate, radiotherapy, renal squamous cell carcinoma, remission.

\section{Introduction}

Renal squamous cell carcinoma ("RSCC") is a rare form of renal cancer which originates from the renal pelvis. RSCC comprises about $0.5-0.8 \%$ of all malignant renal tumours (Bhaijee 2012). Although surgery is sometimes curative for localized disease, metastatic renal squamous cell carcinoma ("mRSCC") is considered incurable (Holmang et al. 2007). Multiple publications from physicians with experience treating RSCC have established that this cancer type is radio-resistant, and that systemic chemotherapy provides little benefit. (Bhandari et al. 2010), (Di Battista et al. 2012), (Kimura et al. 2000), (Li and Cheung 1987). Average survival of advanced stage disease is extremely poor (in the range of several months) and five treatment of congenital lactic acidosis which is comprised of a group of inherited mitochondrial diseases (Stacpoole et al. year survival is reported to be less than $10 \%$ (Holmang et al. 2007). In a review of 15 cases, Lee et al. reported a median survival of 3.5 months (Lee et al. 1998).

A Medline search was conducted (Medline RSCC 2012) to determine if any cases of long-term complete remission of mRSCC had been recorded. This revealed over 200 citations of RSCC but only one published case of 5 year complete remission/cure (Carlson 1960). In this case, the patient had complete nephro-ureterectomy, including resection of peri-renal fat and a cuff of bladder. Pathology did not demonstrate any involvement of surgical margins and there were no metastases reported.

Sodium dichloroacetate ("DCA") is a drug that has been extensively studied for the 2006), (Stacpoole et al. 1992), (Stacpoole et al. 1988). The safety profile of DCA use in humans has been established though this

Copyright (C) 2012 Akbar Khan. This is an open access article distributed under the Creative Commons Attribution License unported 3.0, which permits unrestricted use, distribution, and reproduction in any medium, provided that original work is properly cited. Contact author: Akbar Khan E-mail: akhan@medicorcancer.com 
body of work. It has been found to be a relatively safe drug, with no hematologic, cardiac, pulmonary or renal toxicity. The main toxicity is neurological (primarily peripheral neuropathy) and this is reversible (Kaufmann et al. 2006). DCAinduced delirium has been observed, and is also reversible upon discontinuation of the drug (Brandsma et al. 2010). Minor reversible liver enzyme elevation can occur in a small percentage of patients (Stacpoole et al. 2008).

In January 2007 a landmark paper was published which demonstrated that DCA was effective in treating human breast, lung and brain cancers in vitro and in vivo (rats) by novel metabolic pathways (Bonnet et al. 2007). It was shown that DCA inhibited mitochondrial pyruvate dehydrogenase kinase which resulted in an inhibition of aerobic glycolysis, the usual route for energy production in human cancer cells (known as the Warburg effect). Since cancer cells typically are not able to shift to glucose oxidation when glycolysis is inhibited, DCA-treated cells will be depleted of their ATP energy supply (Xu et al. 2005). It was also demonstrated that DCA triggered apoptosis selectively in cancer cells by a reduction in the membrane potential of hyperpolarized mitochondria and by activation of the voltage-gated potassium channels Kv1.5 (Bonnet et al. 2007).

Since 2007, DCA research has continued and DCA has been shown to have in vitro efficacy against multiple human cancer cell lines including ovarian (Saed et al. 2011), neuroblastoma (Vella et al. 2012), colon
(Tong et al. 2011), lung carcinoid (Fiebiger et al. 2011), cervical (Xie et al. 2011) and endometrial (Wong et al. 2008). Synergism with radiotherapy has also been demonstrated in prostate cancer cell lines (Cao et al. 2008). A mechanism for the synergism proposed by Cao et al. is an increased expression of BCL-2-associated X protein (a pro-apoptotic intracellular protein) which results in an increased rate of apoptosis. DCA also has shown in vivo efficacy in humans against glioblastoma (Michelakis et al. 2010).

The author began to use "off-label" DCA therapy beginning in 2007 for treatment of cancer patients who had a poor prognosis or had failed to respond to conventional cancer therapies. Observation of DCAtreated patients revealed that a significant number appeared to benefit from the use of this drug either by subjective criteria such as pain reduction or objective criteria such as tumor shrinkage (Medicor DCA Data 2009).

\section{Case Presentation}

A 72 year old female presented initially to her family physician with right hip pain, hematuria and weight loss. A mass in the right kidney was diagnosed by ultrasound. A computed tomography ("CT") scan was performed which showed a tumor involving the right renal pelvis, upper and lower poles of the kidney, and extension into the proximal right ureter (Figure 1). There were multiple enlarged lymph nodes in the abdomen (Figure 2). A bone scan was performed which was negative for bone metastases.

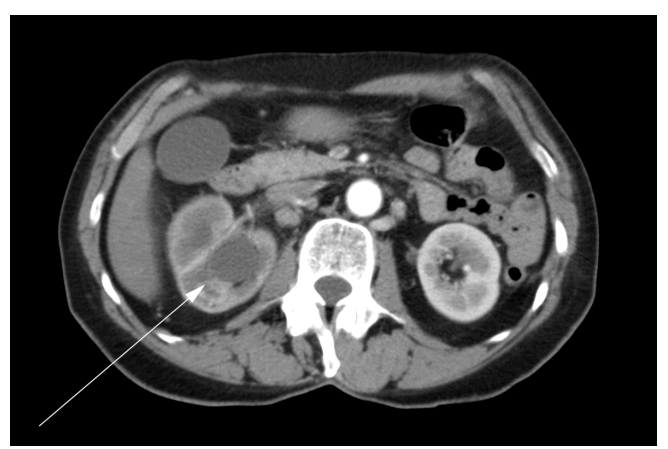

Figure 1 - Abdominal CT scan showing right renal tumor prior to any treatment. 


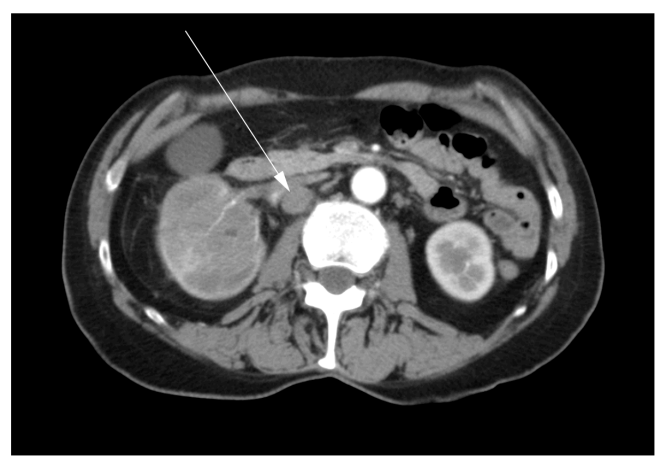

Figure 2 - Abdominal CT scan showing a $2 \mathrm{~cm}$ pathological retroperitoneal lymph node prior to any treatment.

The patient underwent a right radical nephrectomy in May 2007. It was noted in the operative report that a complete excision was not possible. The renal vein was involved and it could not be completely cleared of tumor. Multiple pathologic lymph nodes extending up the vena cava were visualized at the time of surgery but were not removed. An intraoperative biopsy of one of the lymph nodes was conducted. Final histopathology confirmed a diagnosis of renal squamous cell carcinoma with positive surgical margins and lymph node metastases. Postoperatively, the patient was referred for radiation oncology consultation. She received a course of external beam radiotherapy with palliative intent to the para-aortic region of the abdomen with 4500cGy in 25 fractions over 5 weeks from August to September 2007. Medical oncology was consulted, and she was not offered treatment with chemotherapy.

The patient learned of DCA cancer research from her local media, and decided to investigate the option of DCA as ongoing treatment, given her poor prognosis. She attended the author's clinic for DCA therapy consultation.

At the first clinic visit, her complete history was reviewed. Examination revealed a healthy-looking female with normal vital signs and no significant physical findings. Initial blood tests were generally good. The only abnormalities were a mild elevation of urea at 7.4 (normal $3.0-7.1 \mathrm{mmol} / \mathrm{L})$, and a low lymphocyte count of 0.6 (normal 1.2 $3.4 \times 10^{9} / \mathrm{L}$ ). This was not concerning as a mild elevation of urea or creatinine would be expected in a post-nephrectomy patient.

\section{DCA Treatment}

Risks and benefits of DCA were discussed, and the patient consented to DCA treatment which was initiated within 3 weeks following the last fraction of palliative radiotherapy. The patient was started on DCA $500 \mathrm{mg}$ orally twice a day $(18 \mathrm{mg} / \mathrm{kg} /$ day $)$, on a cycle of 2 weeks on / 1 week off. Cyclic treatment was selected due to the author's prior experience with an unacceptable level of side effects in adult patients using continuous DCA dosing. She was prescribed benfotiamine (a lipid soluble form of vitamin B1) $80 \mathrm{mg}$ orally twice a day and R-alpha lipoic acid $150 \mathrm{mg}$ orally 3 times a day to reduce the risk of DCA neuropathy, since both of these natural compounds have proven benefits in treating neuropathy of other etiologies (Ziegler et al. 1999), (Winkler et al. 1999). She was also started on pantoprazole $40 \mathrm{mg}$ orally once a day to prevent stomach upset from DCA. After the first 3 week cycle, the DCA was increased to $500 \mathrm{mg}$ orally three times a day $(27 \mathrm{mg} / \mathrm{kg} /$ day). The dose was raised in stepwise fashion to ensure tolerability because of the reduced metabolism of DCA with advanced patient age (Shroads et al. 2008).

The patient generally felt well during the first month of DCA treatment except for 
mild fatigue, which may also have been a radiotherapy side effect. Even with the increased DCA dose after 3 weeks, no problems were experienced through the second month of therapy. DCA was stopped towards the end of the third month due to new symptoms indicating peripheral neuropathy.
At the time the DCA was stopped, the patient had a triphasic CT scan which showed no evidence of residual cancer. After another 6 months, the patient had a CT scan which again showed no evidence of cancer (Figure 3).

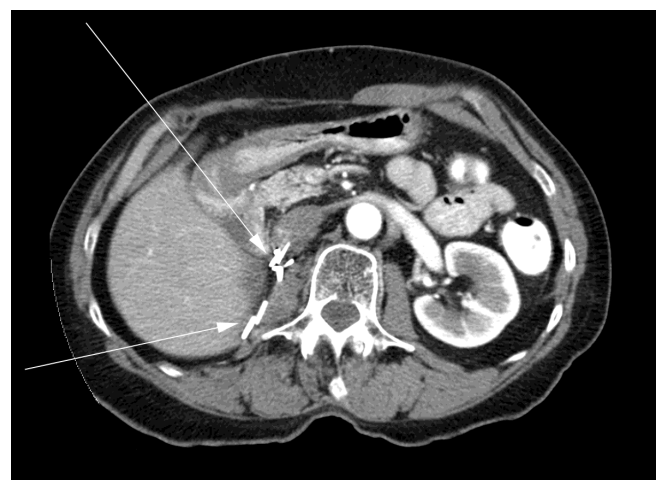

Figure 3 - Abdominal CT scan showing no disease recurrence 6 months after completion of DCA treatment. Arrows show surgical clips in right renal bed post-nephrectomy.

The patient continued to be monitored regularly at the oncology clinic of her local hospital with routine CT scans about every 6 months. The latest CT scan of October 2011 showed no evidence of mRSCC recurrence. A follow-up visit with the radiation oncologist in December 2011 confirmed an absence of recurrence. Physical examination was normal and her performance status was ECOG level 0 . September 2011 marked the 4 year point from radiotherapy and initiation of DCA treatment, and December 2011 marked the 4 year point from completion of 3 months of DCA therapy. As of September 2012, 5 years from the date of initiation of DCA therapy, the patient remains asymptomatic. She received no other cancer treatment during this time (including DCA) given that there was never any evidence of disease recurrence.

\section{Discussion}

We believe this to be the first published case of long-term complete remission (and probable cure) of mRSCC. There is only one similar reported case of 5 year complete remission of RSCC in the Medline-indexed literature dating back 50 years, however that patient did not have metastatic disease. Our case warrants close attention since mRSCC is very aggressive with a median survival in the range of several months with all available conventional therapy.

Radiotherapy alone provides little survival benefit for mRSCC (Holmang et al. 2007). The extended 5 week treatment time of palliative radiotherapy in this case further reduces the chance of cure (unlikely as it is to begin with based on the cancer type) by virtue of reduced cell kill through a process called "accelerated repopulation". Repopulation is defined as the ability of cells within a tissue to replenish following a dose of radiation. Repopulation increases as the total treatment time to deliver a dose of radiation lengthens during a course of fractionated radiotherapy. This effect reduces harm to healthy tissue but also reduces cancer cell kill - consistent with the goal of palliation. Repopulation is most pronounced with a total radiation treatment time of 4-6 weeks and beyond, and this patient received her fractionated radiotherapy over 5 weeks (Abeloff May 21, 2008) .

As noted previously, DCA has synergism with radiotherapy in prostate cancer. The author's experience in treating patients 
with DCA suggests that the synergism with radiotherapy can occur in various types of cancer other than prostate. Examples include: a 53 year old female with a 3 year complete remission of Bartholin's gland carcinoma treated with radiation and adjuvant DCA, and a 32 year old female with a 3 year complete remission of anaplastic astrocytoma following chemoradiation with adjuvant DCA (cases being prepared for publication).

In this case of mRSCC, the adjuvant use of DCA following a course of radiotherapy produced a surprising complete remission, with no detrimental side effects aside from reversible peripheral neuropathy. In this patient, the prophylactic benfotiamine and R-alpha lipoic acid did not abort the development of peripheral neuropathy from DCA. The author now adds acetyl Lcarnitine to the DCA neuropathy prevention regimen, since it also has proven benefits in treating neuropathy of other etiologies, such as diabetic, chemoinduced, and antiretroviral-induced neuropathy (Herzmann et al. 2005), (Quatraro et al. 1995), (De Grandis and Minardi 2002), (Bianchi et al. 2005).

Currently there are no active clinical trials investigating the role of DCA in combination with radiotherapy alone. One trial is currently investigating DCA in combination with chemotherapy and radiation for head and neck carcinoma (Clinicaltrials.gov 2012). Due to the nonproprietary status of DCA, it has been difficult for researchers to raise funds to conduct expensive human trials. It is our hope that publication of clear cases illustrating the benefits of DCA as an adjuvant to traditional cancer therapies will motivate researchers to find creative new fundraising mechanisms so DCA can be formally investigated in further human trials. We hope that DCA will thereby become more widely accepted in the oncology community, and used for the benefit of patients with incurable malignancy.

Since completion of human clinical trials can take many years, in the interim we believe it is ethical to cautiously prescribe "off-label" DCA combined with, or following palliative radiotherapy, for patients who fully understand and accept the risks and benefits. DCA may have a further role as a novel therapeutic approach in combination with radiotherapy for radio-resistant nonmetastatic cancers, but this has yet to be clarified.

\section{Acknowledgement}

The author wishes to thank Dr. Humaira Khan and Dr. Isaac Eliaz for their assistance in preparation of this case report, and also the patient for consenting to publish her case.

\section{Author Disclosure Statement}

The author prescribes cancer treatment medications (including dichloroacetate) that are provided through Medicor Cancer Centres for a cost. This clinic is owned by a family member of the author.

\section{References}

Abeloff, M. D., Armitage, J. O., Niederhuber, J. E., Kastan, M. B. \& McKenna, W. G. (May 21, 2008). Abeloff's Clinical Oncology, 4th Edition, Chapter: Biological Effects of Radiation.

Bhaijee, F. (2012). "Squamous Cell Carcinoma of the Renal Pelvis," Ann Diagn Pathol, 16(2), 124-7.

Bhandari, A., Alassi, O., Rogers, C. \& MacLennan, G. T. (2010). "Squamous Cell Carcinoma of the Renal Pelvis," J Urol, 183(5), 2023-4.

Bianchi, G., Vitali, G., Caraceni, A., Ravaglia, S., Capri, G., Cundari, S., Zanna, C. \& Gianni, L. (2005). "Symptomatic and Neurophysiological Responses of Paclitaxel- or Cisplatin-Induced Neuropathy to Oral Acetyl-L-Carnitine," Eur J Cancer, 41(12), 1746-50.

Bonnet, S., Archer, S. L., Allalunis-Turner, J., Haromy, A., Beaulieu, C., Thompson, R., Lee, C. T., Lopaschuk, G. D., Puttagunta, L., Bonnet, S., Harry, G., Hashimoto, K., Porter, C. J., Andrade, M. A., Thebaud, B. \& Michelakis, E. D. (2007). "A Mitochondria- 
$\mathrm{K}+$ Channel Axis Is Suppressed in Cancer and Its Normalization Promotes Apoptosis and Inhibits Cancer Growth," Cancer Cell, 11(1), 37-51.

Brandsma, D., Dorlo, T. P. C., Haanen, J. H., Beijnen, J. H. \& Boogerd, W. (2010). "Severe Encephalopathy and Polyneuropathy Induced by Dichloroacetate," J Neurol, 257(12), 2099-100.

Cao, W., Yacoub, S., Shiverick, K. T., Namiki, K., Sakai, Y., Porvasnik, S., Urbanek, C. \& Rosser, C. J. (2008). "Dichloroacetate (DCA) Sensitizes Both Wild-Type and Over Expressing Bcl-2 Prostate Cancer Cells in Vitro to Radiation," Prostate, 68(11), 122331.

Carlson, H. E. (1960). "Squamous Cell Carcinoma of the Renal Pelvis: A Five Year Cure," J Urol, 83, 813-4.

Clinicaltrials.Gov (2012). [Online], Available:

http://clinicaltrials.gov/ct2/results?term= dichloroacetate+radiotherapy [accessed Sept 1, 2012].

De Grandis, D. \& Minardi, C. (2002). "Acetyl-L-Carnitine (Levacecarnine) in the Treatment of Diabetic Neuropathy. A LongTerm, Randomised, Double-Blind, PlaceboControlled Study," Drugs R D, 3(4), 223-31.

Di Battista, L., Stio, F., Guarino, S., Galani, A., Maturo, A., Dimko, M., Mancini, M. \& Gallo, P. (2012). "Squamous Cell Carcinoma of the Renal Pelvis with Stones and Inferior Vena Cava Infiltration. Case Report," G Chir, 33(5), 182-5.

Fiebiger, W., Olszewski, U., Ulsperger, E., Geissler, K. \& Hamilton, G. (2011). "In Vitro Cytotoxicity of Novel Platinum-Based Drugs and Dichloroacetate against Lung Carcinoid Cell Lines," Clin Transl Oncol, 13(1), 43-9.

Herzmann, C., Johnson, M. A. \& Youle, M. (2005). "Long-Term Effect of Acetyl-LCarnitine for Antiretroviral Toxic Neuropathy," HIV Clin Trials, 6(6), 344-50.
Holmang, S., Lele, S. M. \& Johansson, S. L. (2007). "Squamous Cell Carcinoma of the Renal Pelvis and Ureter: Incidence, Symptoms, Treatment and Outcome," J Urol, 178(1), 51-6.

Kaufmann, P., Engelstad, K., Wei, Y., Jhung, S., Sano, M. C., Shungu, D. C., Millar, W. S., Hong, X., Gooch, C. L., Mao, X., Pascual, J. M., Hirano, M., Stacpoole, P. W., Dimauro, S. \& De Vivo, D. C. (2006). "Dichloroacetate Causes Toxic Neuropathy in MELAS: A Randomized, Controlled Clinical Trial," Neurology, 66(3), 324-30.

Kimura, T., Kiyota, H., Asano, K., Madarame, J., Yoshino, Y., Miki, K., Abe, K., Hasegawa, T. \& Ohishi, Y. (2000). "Squamous Cell Carcinoma of the Renal Pelvis with Inferior Vena Caval Extension," Int J Urol, 7(8), 3169; Discussion 320.

Lee, T. Y., Ko, S. F., Wan, Y. L., Cheng, Y. F., Yang, B. Y., Huang, D. L., Hsieh, H. H., Yu, T. J. \& Chen, W. J. (1998). "Renal Squamous Cell Carcinoma: CT Findings and Clinical Significance," Abdom Imaging, 23(2), 203-8.

Li, M. K. \& Cheung, W. L. (1987). "Squamous Cell Carcinoma of the Renal Pelvis," J Urol, 138(2), 269-71.

Medicor (DCA Data 2009) [online], Available: www.medicorcancer.com/DCAdata.html [accessed Oct 1, 2012]. Medline (RSCC 2012) [online], Available: http://www.ncbi.nlm.nih.gov/pubmed, Search Criteria: Renal [title] oR kidney [Title] and ("Squamous Cell Carcinoma"[Title]) [Accessed Oct 1, 2012].

Michelakis, E. D., Sutendra, G., Dromparis, P., Webster, L., Haromy, A., Niven, E., Maguire, C., Gammer, T. L., Mackey, J. R., Fulton, D., Abdulkarim, B., McMurtry, M. S. \& Petruk, K. C. (2010). "Metabolic Modulation of Glioblastoma with Dichloroacetate," Sci Transl Med, 2(31), 31 ra34.

Quatraro, A., Roca, P., Donzella, C., Acampora, R., Marfella, R. \& Giugliano, D. (1995). "Acetyl-L-Carnitine for 
Symptomatic Diabetic Neuropathy," Diabetologia, 38(1), 123.

Saed, G. M., Fletcher, N. M., Jiang, Z. L., AbuSoud, H. M. \& Diamond, M. P. (2011). "Dichloroacetate Induces Apoptosis of Epithelial Ovarian Cancer Cells Through a Mechanism Involving Modulation of Oxidative Stress," Reprod Sci, 18(12), 125361.

Shroads, A. L., Guo, X., Dixit, V., Liu, H. P., James, M. O. \& Stacpoole, P. W. (2008). "Age-Dependent Kinetics and Metabolism of Dichloroacetate: Possible Relevance to Toxicity," J Pharmacol Exp Ther, 324(3), 1163-71.

Stacpoole, P. W., Gilbert, L. R., Neiberger, R. E., Carney, P. R., Valenstein, E., Theriaque, D. W. \& Shuster, J. J. (2008). "Evaluation of Long-Term Treatment of Children with Congenital Lactic Acidosis with Dichloroacetate," Pediatrics, 121(5), E1223-8.

Stacpoole, P. W., Kerr, D. S., Barnes, C., Bunch, S. T., Carney, P. R., Fennell, E. M., Felitsyn, N. M., Gilmore, R. L., Greer, M., Henderson, G. N., Hutson, A. D., Neiberger, R. E., O'Brien, R. G., Perkins, L. A., Quisling, R. G., Shroads, A. L., Shuster, J. J., Silverstein, J. H., Theriaque, D. W. \& Valenstein, E. (2006). "Controlled Clinical Trial of Dichloroacetate for Treatment of Congenital Lactic Acidosis in Children," Pediatrics, 117(5), 1519-31.

Stacpoole, P. W., Lorenz, A. C., Thomas, R. G. \& Harman, E. M. (1988). "Dichloroacetate in the Treatment of Lactic Acidosis," Ann Intern Med, 108(1), 58-63.

Stacpoole, P. W., Wright, E. C., Baumgartner, T. G., Bersin, R. M., Buchalter, S., Curry, S. H., Duncan, C. A., Harman, E. M., Henderson, G. N., Jenkinson, S. \& Et Al. (1992). "A Controlled Clinical Trial of Dichloroacetate for Treatment of Lactic Acidosis in Adults. The Dichloroacetate-Lactic Acidosis Study Group," N Engl J Med, 327(22), 1564-9.

Tong, J., Xie, G., He, J., Li, J., Pan, F. \& Liang, H. (2011). "Synergistic Antitumor Effect of Dichloroacetate in Combination with 5-
Fluorouracil in Colorectal Cancer," J Biomed Biotechnol, 2011, 740564.

Vella, S., Conti, M., Tasso, R., Cancedda, R. \& Pagano, A. (2012). "Dichloroacetate Inhibits Neuroblastoma Growth by Specifically Acting Against Malignant Undifferentiated Cells," Int J Cancer, 130(7), 1484-93.

Winkler, G., Pal, B., Nagybeganyi, E., Ory, I., Porochnavec, M. \& Kempler, P. (1999). "Effectiveness of Different Benfotiamine Dosage Regimens in the Treatment of Painful Diabetic Neuropathy," Arzneimittelforschung, 49(3), 220-4.

Wong, J. Y. Y., Huggins, G. S., Debidda, M., Munshi, N. C. \& De Vivo, I. (2008). "Dichloroacetate Induces Apoptosis in Endometrial Cancer Cells," Gynecol Oncol, 109(3), 394-402.

Xie, J., Wang, B. S., Yu, D. H., Lu, Q., Ma, J., Qi, H., Fang, C. \& Chen, H. Z. (2011). "Dichloroacetate Shifts the Metabolism from Glycolysis to Glucose Oxidation and Exhibits Synergistic Growth Inhibition with Cisplatin in Hela Cells," Int J Oncol, 38(2), 409-17.

Xu, R. H., Pelicano, H., Zhou, Y., Carew, J. S., Feng, L., Bhalla, K. N., Keating, M. J. \& Huang, P. (2005). "Inhibition of Glycolysis in Cancer Cells: A Novel Strategy to Overcome Drug Resistance Associated with Mitochondrial Respiratory Defect and Hypoxia," Cancer Res, 65(2), 613-21.

Ziegler, D., Hanefeld, M., Ruhnau, K. J., Hasche, H., Lobisch, M., Schutte, K., Kerum, G. \& Malessa, R. (1999). "Treatment of Symptomatic Diabetic Polyneuropathy with the Antioxidant Alpha-Lipoic Acid: A 7-Month Multicenter Randomized Controlled Trial (ALADIN III Study). ALADIN III Study Group. Alpha-Lipoic Acid in Diabetic Neuropathy,' Diabetes Care, 22(8), 1296-301. 